\title{
Misery Implicitly Loves Company: Implicit Homophily and Bully Victimization
}

Yasmine Saraf $^{1}$, Laureen Khalil ${ }^{1}$, Jarryd Willis ${ }^{1}$, Samantha Yim ${ }^{1}$, Gareth Disler ${ }^{2}$, Jiani $_{\text {Li }}{ }^{1}$, \& Tugral Bek Awrang Zeb ${ }^{3}$

${ }^{1}$ Department of Psychology, The University of California, San Diego, San Diego, California, United States of America

${ }^{2}$ The University of Central Florida, College of Medicine

${ }^{3}$ San Diego Mesa Community College

Acknowledgements: We would like to thank Avital Simanian, Daniel Javidi, Krishina Mirpuri, Sceptre Ganasi, Margaret Satchwell, Marissa Hensley, Laila Lawson, Mykel Rodriguez, Nicole Tanzer, \& Chris Taves for their support at different points of this project.

\section{Author Note}

Jarryd Willis XXXXXX(Orcid link)

We have no conflicts of interest to disclose.

Correspondence concerning this article should be addressed to

Jarryd Willis, 9500 Gilman Dr., La Jolla, CA 92093.

Email: Jarryd.Willis@gmail.com 


\begin{abstract}
This study focuses on the formation of bullied individuals' friendships and romantic relationships. Individuals bullied in their past may be more likely to form connections with those who share similar oppressive experiences. Thus, we investigated the possibility that implicit homophily underlies the formation of interpersonal relationships amongst previously bullied individuals. Moreover, we investigated whether these individuals were aware of their friends' and romantic partners' similarly oppressive experiences prior to initiating the relationship. Our findings suggest that the young adults in our sample bullied in grade school are significantly more likely to have a close friend and or significant other who also experienced bullying. The findings of this study contribute to the relatively small, yet growing, body of research on implicit homophily, add to research extending homophily processes to bullies and victims, and are in line with research suggesting that deselection (a form of induced homophily) can coexist with homophily by personal preference.
\end{abstract}

Keywords: homophily, bully victimization, interpersonal relationships 


\section{Misery Implicitly Loves Company: Implicit Homophily and Bully Victimization}

Homophily, which is the sorting of social ties into groups that match various

sociodemographic features, is a well-documented phenomenon (McPherson et al., 2001). Two ways in which homophilous groups may form result from choice or induction (Huber \& Malhotra, 2013; McPherson et al., 2001). Choice homophily denotes groups that form based on salient characteristics, socially expressed cues, and symbolically interactive markers of identity. The groups that one is born into are the most powerful of these. Race-homophily is quite possibly the most substantial component of group formation (Kao \& Joyner, 2004; Lewis \& Kaufman, 2018; Mayer \& Puller, 2008; McPherson et al., 2001; Messias et al., 2017; Quillan \& Campbell, 2003; Wejnert, 2010), followed by (in no specific order) sex (Hofstra et al., 2017; Messias et al., 2017; Smith et al., 2014), ethnicity (Hofstra et al., 2017; Smith et al., 2014; Syed \& Juan, 2012; Vervoort et al., 2011), and sexual orientation (Galupo, 2007; Logan, 2013; Ueno et al., 2012). Homophily also forms based on chosen groups from which one extracts a sense of self-esteem and nests one's self-concept, such as religion (McPherson et al., 2001), sports fandom (Phua, 2012), political orientation (Alford et al., 2011; Allen \& Post, 2004; Huber \& Malhotra, 2017), and gender identity (Mehta et al., 2017). Furthermore, homophily with groups that one achieves identification with is potentially established due to (but not limited to): educational attainment (Skopek et al., 2011) and prestige among university faculty (Evans et al., 2011), fitness and weight loss (Crosnoe et al., 2008; Robinson, 2016), and grouping with similarly high achieving players in massive multiplayer online role-playing games (Utz \& Jankowski, 2015).

In contrast, induced homophily manifests as a result of the social structural pressures/constraints of one's current situation (Huber \& Malhotra, 2013; McPherson et al., 
2001). For instance, homophilous perceptions of an emergency may lead a group of random individuals to form rapidly, albeit briefly, with a collective goal of rescuing, protecting, or otherwise responding to the situation (Alstott et al., 2014). Induced homophily may also form based on current personal challenges, such as group membership required by law (e.g., someone with a DUI attending mandatory Alcoholics Anonymous meetings) or membership organized within a healthcare facility (i.e., breast cancer inpatient support groups) (Andersen et al., 2008; Wright, 2000).

Induced homophily further manifests when individuals become excluded from consideration for inclusion in other social circles. For instance, a depressed high school student may be evaluated as unappealing and consequently deselected by their peers (Rudolph et al., 2008). Indeed, research has found evidence of deselection homophily among depressed youth (Schaefer et al., 2011), individuals who have engaged in self-injury (Prinstein et al., 2010), and psychopathology (Mercer \& DeRosier, 2010). More recently, a Canadian study of international students' decisions to form close bonds with others of the same ethnic background or other international students (even if they were not of the same race/ethnicity) was primarily due to their descriptions of Canadian-born students rejecting them in unstructured social interactions (Robinson et al., 2020). Thus, while followers of Catholicism may show religious homophily clearly as a result of their preference for people who follow the same faith (McPherson et al., 2001), the phenomenon of homophily within breast cancer inpatient support groups (Andersen et al., 2008) and racial/ethnic homophily among international students (Robinson et al., 2020) takes place "in the absence of preference" (Schaefer et al., 2011, p. 766).

In addition, homophily may also result from a process known as socialization, whereby individuals in a social relationship become more similar over time (Stevens \& Prinstein, 2005). 
For example, longitudinal research on best friends has found that the depression experienced by one friend has a contagion effect on the other, such that the correlation in their two depression scores increases over time. Similar socialization patterns have been reported for political orientation (Jennings et al., 2009), religious orientation (Patacchini \& Zenou, 2016), and depression contagion in parent-child relationships and married couples (Hammen et al., 1991; Joiner \& Katz, 1999).

The present study investigated a relatively understudied form of homophily known as Implicit Homophily. This phenomenon (which is conceptually similar to Background Homophily; McCroskey et al., 1975) is characterized as individuals forming a social bond (whether friendship, romantic relationship, or larger group identity) on the basis of their similarity on non-salient personal factors (Jacoby-Senghor, 2014; McCroskey et al., 2007). For instance, if person A and B are at a social event and music starts playing that neither of them likes, they may notice that they are the only two people not dancing. In this case, the cue of subjective similarity (similar dislike of the current song) was communicated implicitly by a comparison of their body language to everyone else's. Thus, even non-verbal behavioral cues can create a sense of a shared identity with others.

Similarly, individuals who had interracial friendships during high school are more likely to form interracial friendships in college with peers who also had interracial friendships in high school (Mayer \& Puller, 2008; Stearns et al., 2009). Moreover, individuals who previously had cross-sexuality friendships (e.g., straight male - gay female) were more likely to make friends across multiple intergroup dimensions in college (Goldstein, 2013). Even genetics research found homophily among individuals with similar polymorphic alleles on the dopamine D2 receptor DRD2 (Fowler et al., 2011). Given that peers' polymorphisms are not easily discernible 
when interacting, the finding of genotype-level homophily suggests that some phenotypic behavior(s) signals similarity to peers bearing genotypic resemblance. Another study found that participants' perceived similarity with same-race peers was associated with their degree of antiBlack implicit bias (Jacoby-Senghor, 2014). The study's author poignantly noted that “...it is not objective behavior per se that is important, but rather the message about the targets' subjective experiences that those behaviors imply" (Jacoby-Senghor, 2014, p. 54).

Overall, all three forms of homophily discussed above (choice homophily, induced homophily, and implicit homophily) allude to the tendency individuals have to form relationships with those who are similar to themselves; however, each form of homophily uniquely manifests itself (Huber \& Malhotra, 2013; Jacoby-Senghor, 2014; McCroskey et al., 2007; McPherson et al., 2001). Choice homophily relies on salient markers such as race and ethnicity to drive the formation of social relationships. Induced homophily does not depend on such apparent characteristics, instead driven by similarities in social situations and personal goals. In each of these instances, however, relationships form based on explicit qualities, structural constraints, and situational factors. With implicit homophily, connections form between individuals with similar backgrounds despite the absence of any universally recognizable salient markers.

\section{Oppression Homophily}

Our investigation focuses on group formations based on past oppressive experiences of bullying and on individuals who have engaged in self-harm. Of particular interest was the degree to which the friendships formed due to explicit characteristics (whether phenotypic or cosmetic) shared between the individuals, or if sharing a history of such oppressive experiences would affect individuals in such a way that they send and receive implicit cues of similarity. As 
previous research has shown, shared experiences of oppression is an attribute, similar to shared religion and shared political affiliation, that generates homophily (Cortland et al., 2017; Distel et al., 2010; Logan, 2013).

For instance, Distel et al. (2010) found that lonely individuals tend to form pair-bonds with individuals who share a similarity in their loneliness experience. Joiner (1999) found evidence of homophily among individuals who engaged in self-harm. Moreover, shared subjective experiences (bullying and loneliness) increases fondness of others more than shared objective experiences (salient group categorizations) and thus may explain the strength of implicit homophily (Distel et al., 2010; Pinel et al., 2006; Pinel \& Long, 2012).

As such, we predict that individuals who have experienced bullying and engaged in selfharm would display a tendency towards forming close bonds with one another. However, few studies have investigated implicit homophily concerning oppressive past experiences of peer victimization and self-harm. Thus, addressing that gap was the aim of the current study.

\section{Bullying \& Peer Victimization}

Bullying is a form of aggression that is intentional, repetitive, and occurs in the context of a power imbalance between the perpetrator and the victim (Olweus, 1994). Bullying can be further broken down into specific subcategories, including physical bullying and verbal bullying (Rivers \& Smith, 1994), cyberbullying (Hinduja \& Patchin, 2010), and social bullying (Borowsky et al., 2013).

Bullying is a prevalent malignancy in America's public-school system (Hatzenbuehler et al., 2015) and is negatively associated with individual's mental health and well-being (Swearer et al., 2010), physical health (Greco et al., 2007), academic performance (Juvonen et al., 2000; Macmillan \& Hagan, 2004; Peguero, 2011), and social identity development (DeVoe et al., 2005; 
Peguero \& Williams, 2011; Williams et al., 2000; Williams \& Sommer, 1997). Research consistently reports associations between being a victim of bullying and the internalization of depression, anxiety, and negative self-perceptions (Meland et al., 2010; Swearer et al., 2010). Consistent with the literature mentioned above, bullies show homophilous affiliation patterns (Cairns et al., 1988).

There may be various explicit factors associated with an individual's experience of bully victimization. For instance, research illustrates that bullied students usually possess a salient physical feature (e.g., obesity, racial minority, glasses, disability; Iyer-Eimerbrink \& JensenCampbell, 2019; Qureshi, 2011; Turner et al., 2011) not socially reinforced. Thus, it is reasonable to consider that oppression homophily may result from (1) salient physical characteristics, such as obesity, that make someone a less appealing social partner and (2) the emotionally dysregulated behavior of some bullied or depressed individuals may drive others away. Thus, we assessed the degree to which various explicit characteristics influenced friendship patterns among bullied and non-bullied participants.

Given the importance of social relationships in meeting the need for belongingness, it is reasonable to consider that humans develop implicit cues to potential group similarity or likelihood of social affinity. The utility of such cues would be ascertained incrementally in proportion to the redeeming value of the social connections they enable us to form. This implicit homophily in friendship formation is potent in that it transverses real-life interactions into the virtual and online context. For example, individuals who play Massively Multiplayer Online Role-Playing Games (MMORPG) connect online without explicitly or personally knowing one another. The manifestation of implicit homophily is perhaps summarized best by Lou et al. (2013) upon the realization that male and female MMORPG players are more likely to make 
corporeal same-sex friends despite the fact that all they can see in the game is the other player's non-corporeal avatar (which often is not the same sex as the actual player): "Since players are not told of the real gender of other players and can only see the avatar gender, this appears to indicate the possibility that a subconscious, implicit selection process may be at work" (p. 834).

\section{Been Through It}

Some facets of individuals' self-concept are more chronically accessible than others (Bargh et al., 1988). For instance, a mother or father's self-concept of being a parent is chronically accessible. Chronically accessible means that whether they are grocery shopping, in an office meeting, or taking an exam, they will immediately change ongoing plans if they receive a call from the school indicating their child suffered an injury during recess. In essence, the critical social identities we carry (i.e., being a parent) and significant favorable/adverse events of our lives can become chronically accessible. Such events weave themselves into the fabric of who we are. We argue that being a victim of bullying may be a chronically accessible component of someone's self-concept (Rosen et al., 2007).

Chronically accessible components of one's self-concept should be particularly sensitive to and discerning of relevant cues (regardless of their intended salience) from others (Neuberg \& Sng, 2013). For example, someone who feels cheated in a previous transaction may perceive the smiling car salesman as someone preparing to tell yet another lie. In this instance, the person is hypervigilant to cues of deceit, perhaps even to the extent that they will judge an otherwise honest salesperson as having duplicitous intentions.

Whether or not someone has engaged in self-harm can be considered a chronically accessible facet of the self as well. The maladaptive and unhealthy strategy of self-harm may be utilized by some individuals due to the neural overlap in how the brain processes physical and 
social pain (Eisenberger, 2012). Indeed, the "neural overlap causes an incidental effect where physical pain offset simultaneously generates emotional pain offset” (Franklin et al., 2013, p. 116). As such, the emotional pain experienced by victims of bullying may make them more likely to engage in self-harm, making this a potential factor in assortative relations among those individuals.

Taken together, we reasoned that if oppressive experiences such as peer victimization are chronically accessible components of someone's self-concept, then it should be the case that bullied individuals should be more likely than others to form social bonds with peers who have been through it as well.

\section{Overview of Current Research}

\section{Bullying Hypotheses}

Many individuals recover from the psychically damaging experience of bully victimization. However, as is the case with physical wounds, bullying leaves an emotional scar etched onto someone's self-concept in such a way that it influences future social interaction patterns. Thus, the present study investigates if the interpersonal relationship formation patterns of bullied individuals reflect implicit homophily, thereby leading two experientially similar individuals to develop interpersonal bonds at a high rate, even without knowing that they share an oppressive history. From this, we formed the following hypotheses.

Hypothesis 1: Friendships. We predicted that individuals who have been bullied would be more likely than those who have not to form friendships with individuals who have also been bullied. 
Hypothesis 2: Romantic Relationships. We predicted that individuals who have been bullied would be more likely to form a romantic relationship with a peer who was also bullied than individuals who have not been bullied.

Hypothesis 3: Self-Harm. Consistent with Prinstein et al. (2010), we predicted that individuals who have engaged in self-harm would be more likely to have friends who have also engaged in self-harm than individuals who have not.

\section{Exploratory Analyses}

Though we made no formal hypotheses regarding deselection homophily, the literature, as mentioned earlier, suggests that individuals who have been bullied conduct themselves in such a way that results in surrounding themselves with others who have similar experiences of peer victimization (Prinstein et al., 2010). Individuals may find themselves in this position because (1) the broader peer network ostracized them and constrained their social choices, or (2) the experience of bully victimization leads them to desire other marginalized peers even without initially being aware that they share that painful history or both. Thus, we decided to assess participants on the different dimensions of bullying. This included the degree to which physical appearance led to bullying, different rates of bullying based on race/ethnicity, and someone's openness to befriending a peer with perceivably unpopular characteristics (e.g., drives an ugly car, eats alone in the cafeteria, engaged in self-injury, rarely eats, deleted their social media, materialistic, and opposition to alcohol consumption). These seven facets were considered and chosen in an exploratory manner.

A potential alternative outcome may be imperfect homophily. For instance, Cawley et al. (2006) found that obese individuals would rather remain sexually inactive than form a romantic relationship with another obese person. Thus, individuals who have been bullied and engaged in 
self-harm may avoid forming platonic and romantic relationships with peers who have had similar experiences. From a social utilitarian perspective, there is more social capital to be obtained from forming a social bond with someone who is socially popular than from someone who has faced similar oppression at their peers' hands. Indeed, a risk-averse social auditor may determine that bonding with such a person would be a net cost on their overall social capital. 


\section{Methods}

\section{Participants}

Participants were 192 undergraduate students (121 female; $M_{\text {age }}=20.25, S D_{\text {age }}=2.1,18$ to 26) at a large, western U.S. university. The ethnoracial composition of the sample was as follows: 59.8\% Asian, 19.0\% Hispanic, $13.0 \%$ White, 5.98\% Mixed, and 2.17\% Black. Participants registered for the study through an online study recruitment platform known as the SONA system (Fidler, 1997). The SONA system allows students taking social science classes to browse different ongoing studies and to select the ones that they would like to participate in. As compensation for their participation, students received one hour of credit towards their lowerdivision Psychology research requirement.

\section{Procedure}

Participants completed a 15-page, 85 question, questionnaire packet in a bright and quiet room. The questionnaire evaluated participants' basic demographic information, their personal experience with bullying, as well as their current and past interpersonal relationships. The duration of the time spent on the survey was approximately one hour. All participants completed an informed consent form before receiving and beginning the survey. After participants completed the questionnaire material, they were debriefed about the study and assigned research credit.

\section{Measures}

\section{Bully Victimization}

Participants completed a qualitative item asking them to define what bullying means to them in a few sentences. They then completed several dichotomous items asking if they were bullied in the past, a current victim of bullying, bullied in high school, and bullied in college. 
They then completed items asking them to specify which grades of high school, which grades of college, and which broad form(s) of bullying they experienced (physical, verbal, social, and cyber). The following definitions were provided to participants for each broad classification of bullying: physical (hitting, kicking, stealing/damaging personal things), verbal (name calling, teasing, intimidation, verbal abuse), social (spreading rumors, encouraging others to exclude you, damaging your reputation or social acceptance), and cyber (bullying on social media, the internet, via texts).

In addition, participants were asked how frequently the bullying occurred, the location where it occurred the most, and the reason(s) (if any) that they believe they were targeted. The options included: physical attributes, personality traits, inability to do certain activities well, disabilities, socioeconomic status, being friends with someone who was not well-liked, clothes, note sure, and other as a qualitative option in which participants could write in a response that was not listed.

\section{Impact of Bullying}

Participants completed items assessing how bullying impacted their participation in school activities, grades, attendance, asking questions in class, self-esteem, willingness to express the experience to friends and family, and willingness to befriend an individual with lower socioeconomic or psychosocial standing. Each of these items were completed on a sevenpoint Likert-type scale $(1=$ lowest agreement/least impact $\mathrm{vs.} 7=$ highest agreement/greatest impact).

\section{Close Friendships \& Relationships}

We operationally defined a close friend as a friend in which the participant is subjectively able to trust and rely on in their relationship. Furthermore, we defined a significant other as an 
individual in which the participant has established a romantic or intimate (e.g., boyfriend or girlfriend) relationship with.

Participants were assessed on whether they were in a romantic relationship with someone and close friendship with someone who was previously a victim of bullying, whether they were aware of their past before befriending them, and whether their significant other or close friends were aware of their previous victimization of bullying beforehand. Participants' responses to these questions were assessed on a nominal scale indicating either "yes" or "no." Afterward, participants were assessed on whether all of their friends were currently aware of their previous bullying history, based on a five-point Likert-type scale $(1=$ no friends are aware vs. $5=$ all friends are aware).

Participants were specifically asked how many friends they made solely on their shared history of being bullied to try to avoid reporting bias. The participants' responses indicated whether their shared history was significant (due to implicit similarity) or an outside factor influenced their friendship formation.

\section{Self-Harm}

Participants were assessed on whether they have thought about harming themselves in the past. In addition to this, participants were questioned on if they harmed themselves intentionally. Participants' responses to these questions were assessed on a nominal scale indicating either "yes" or "no." Furthermore, participants were asked how many of their close friends have selfharmed, as well as whether they knew anyone personally (excluding their close friends) who have self-harmed. Participants' responses were assessed on a five-point Likert-type scale $(0=n o$ individuals have self-harmed vs. $5=$ more than 5 individuals have self-harmed). 


\section{Results}

All participants were surveyed on a nominal scale on whether they were bullied in their past or not. A total of 106 participants reported that they had been bullied in the past; 11 participants specifically reported that they were bullied in high school, and 6 participants reported that they were bullied in college. In addition to this, 121 participants reported a close friend who was bullied in the past.

To avoid reporting bias, participants were surveyed on how many friends they made solely on their shared history of being bullied. A chi-square test of independence found that regardless of how many friendships were formed between previously bullied participants, there was no significant correlation, $\chi^{2}(1, N=86)=2.994, p>.001$.

\section{Hypothesis 1: Friendship}

Consistent with our first hypothesis, a chi-square test of independence found a significant effect for bully victimization and friendship formation, $\chi^{2}(1, N=177)=19.93, p<.001$. As illustrated in Figure 1, previously bullied individuals were significantly more likely to have a close friend who was also bullied $(71.1 \%)$ compared to those who reported not being bullied (28.9\%). A subsequent chi-square, conducted to determine whether this friendship was formed based on (or with consideration of) explicitly disclosed information of having been a victim of bullying, was not significant, $\chi^{2}(1, N=136)=.02, p=.894$. This suggests that they were not aware that their friends had been victims of bullying prior to the formation of the friendships.

\section{Hypothesis 2: Romantic Relationship}

In line with our second hypothesis, a chi-square test of independence found a significant effect for bully victimization and romantic relationship formation, $\chi^{2}(1, N=186)=7.82, p=$ .005. As illustrated in Figure 2, previously bullied individuals were more likely to have a 
romantic partner who had been bullied (81.8\%) compared to those who reported not being bullied (18.2\%). A subsequent chi-square, conducted to determine whether this romantic relationship formation was implicit or explicit, was not significant, $\chi^{2}(1, N=64)=2.54, p=$ .111. This suggests that these participants were not aware of their romantic partners' bullying history before they became couples.

We extended these analyses to determine whether this implicit friendship and romantic partner formation differed between males and females. A set of four chi-square tests of independence (two for women and two for men) found that the significant findings for friendship formation based on bullying history were unchanged, but sex was a relevant factor in the formation of bullied individuals' romantic relationships. Males indicated that they had formed a relationship with someone who had a history of being bullied $\left[\chi^{2}(1, N=119)=7.54, p=.006\right]$, but females did not $(p=.26)$.

\section{Hypothesis 3: Self-Harm}

Consistent with our third hypothesis, a chi-square test of independence found that the likelihood of befriending someone who previously self-harmed was significantly associated with respondents' self-harm history, $\chi^{2}(1, N=146)=8.56, p=.003$. As illustrated in Figure 3 , individuals who previously self-harmed were far more likely to befriend peers who had selfharmed $(74.1 \%)$ than individuals with no history of self-harm $(42.9 \%)$.

\section{Exploratory Analyses}

\section{Physical Attractiveness}

In a study on imperfect homophily, Cawley et al. (2006) found that obesity reduced girls' chances of entering a dating relationship but did not significantly reduce their chances of having sex. In disambiguating the findings between dating and sex, the authors astutely noted "that peers 
observe one's dating partners but not necessarily one's sex partners" (Cawley et al., 2006, p. 87). In essence, the clandestine nature of sexual relations meant that having an obese sexual - but not romantic - partner poses "less risk to one's reputation" (Cawley et al., 2006, p. 87).

The present study revealed a conceptually similar pattern. Specifically, women who reported being bullied based on their physical attractiveness were more likely to be in a romantic relationship with someone who was also bullied based on their physical appearance, $\chi^{2}(1, N=$ $69)=6.82, p=.009$. However, for men, there was no pattern to suggest that males who had been bullied based on their physical attractiveness were more likely to be with a significant other bullied for a similar reason.

\section{Deselection vs. Preference}

Lastly, we assessed the degree to which interpersonal relationships formed between bullied individuals based on deselection (constrained options due to no longer being desired by peers) and preference (perhaps bullied individuals desire befriending individuals with qualities non-bullied students would find undesirable). A MANOVA was conducted on the seven dependent variables (drives an ugly car, eats alone in the cafeteria, engaged in self-injury, rarely eats, deleted their social media, materialistic, and opposition to alcohol consumption) to determine their association with participants' history of being bullied. The omnibus MANOVA, based on the Wilks Lambda criterion, failed to find a significant main effect between the variables $(p=.219)$. However, there was a univariate main effect for bullying history on willingness to befriend someone who engages in self-harm, $F(1,187)=4.35, p=.038, \eta^{2}=$ 2.3\%. Willingness to befriend someone who engages in self-harm was higher for bullied respondents $(M=4.9, S E=.2)$ than for non-bullied respondents $(M=4.2, S E=.2)$. A RoyBargmann Stepdown Analysis was not conducted as no other main effect was found. 


\section{General Discussion}

In the present study, we sought to determine if someone previously bullied was more likely to befriend or start a romantic relationship with an individual who shares a mutually oppressive history of bully victimization. Individuals who experience emotional pain, such as loneliness, may exhibit cues (e.g., nonverbal behaviors) that attract others with a similar history (Cacioppo et al., 2006). Research further illustrates that the experience of loneliness is an aversive state similar to hunger, and thus individuals are motivated to satiate their social appetite using readily accessible resources (Cacioppo et al., 2003; Eisenberger \& Lieberman, 2004). Just as people may consume less than ideal food sources during times of starvation, the socially starved individual may relax their standards and preferences for interpersonal affiliation during a period of social famine. As a result, the likelihood of establishing meaningful relationships with peers who have had similar oppressive experiences may increase without the explicit expression or conscious awareness of the motivation to do so.

Consistent with our first hypothesis, we found that bullied individuals were more likely to befriend someone who had previously been bullied. Next, in support of our second hypothesis, we found that bullied individuals were more likely to date someone who had previously been bullied. However, subsequent analyses conducted based on sex revealed support for our second hypothesis for males only.

These findings can potentially be explained from an evolutionary and gender socialization theoretical perspective, as men may want to play hero for a bullied female, while women may assess a male who cannot protect himself as possessing low mate value. Therefore, women may reject bullied potential-partners to find a mate who can better-protect them (an evolutionarily based strategy) or avoid social repercussions from being associated with a socially 
undesirable partner (a gender socialization based strategy). It may also be the case that women will dismiss previously bullied partners due to characteristics associated with being bullied in adolescence and young adulthood (e.g., lack of muscle mass, unattractive appearance, etc.). Please note, however, that these are just considerations and that any decisive stance is beyond the scope of this study. Selecting a romantic partner is a multifaceted decision based on a complex interplay of individual preferences, attraction, and social factors. In terms of the latter aspect, women may place greater importance on bullying than men. It is also the case that heterosexual men may be more open to dating a woman who was a victim of bullying due to gender socialization (e.g., the ubiquitous portrayal of the knight saving the damsel in distress). Future research on this topic may elucidate the degree to which women and men consider prior bully victimization in their mate preferences.

In addition, we sought to determine if the formation of their friendships and romantic relationships was due to explicit self-disclosure of their bully victimization histories, or if they formed the respective relationships prior to disclosing that they were both bullied or engaged in self-harm. Indeed, participants reported that the relationships formed despite not explicitly seeking out individuals with similar oppressive experiences, and without the disclosure of those experiences in their relationship formation. In short, the formation of their friendships and romantic relationships was partially the result of implicit homophily in that those who have similar past experiences are more likely to form social relationships with one another than those who do not. Although we agree that both choice and induced homophily play a significant role in the formation of friendships and romantic relationships, our data suggests that implicit characteristics also have an effect. 
Consistent with research showing homophily among individuals who have engaged in self-harm (Prinstein et al., 2010), the current study found that individuals who have engaged in self-harm were more likely to have friends who have engaged in it as well. Moreover, individuals who had not engaged in self-harm were significantly less likely to indicate having a friendship with someone who had. These findings regarding self-harm remain significant regardless of victimization history. That is, significant findings for self-harm homophily remain even among individuals who report not having experienced bullying.

Furthermore, we sought to evaluate the degree to which interpersonal relationships formed between bullied individuals based on deselection and preference. The findings suggest that preference may play a more significant role than deselection in the formation of bullied individuals' interpersonal relationships. While there might be some degree of deselection, in which previously bullied individuals become isolated due to their undesirable social status, there is a significant trend in which bullied individuals are gravitating towards others with a history of bully victimization history in their friendship formation.

However, in contrast to friendship formation, both bullied and non-bullied individuals were more likely to be in a romantic relationship with someone who was not bullied. To be clear, bullied individuals were more likely to date someone who was bullied than non-bullied individuals, but their propensity to form friendships with similarly bullied peers was belied by their propensity to form romantic relationships with non-bullied peers. Though we lack the full social network data to make a stronger assertion, we feel that the difference illustrated in the comparison between Figures 1 and 2 is indicative of a preference on the part of bullied individuals. Indeed, the preference for non-bullied lovers was similar to the preference for 
bullied friends. It is unlikely that the trend would be that sharp if deselection was the primary driver of bullied individuals' interpersonal bonds.

It is possible, however, that both preference and deselection may play a role in the context of self-harm homophily. Individuals bullied in the past may have a better understanding of why bully victimization may incline a victim to engage in self-harming behavior, and thus they would not view such a characteristic as undesirable. Indeed, it may be the case that bullied individuals would find such behavior understandable, and individuals who had previously engaged in self-harm (even if bullying was not a precursor) may find it relatable. On the other hand, non-bullied students may be more likely to consider self-harming behavior too out of the ordinary for their liking, making it undesirable. Specifically, befriending an individual that has self-harmed may require a high degree of empathy specific to that emotional context; empathy that may require more effort for individuals without histories of bully victimization or self-harm to generate given their lower likelihood of experiencing an emotional context of that nature.

Research investigating ingroup-outgroup gaps in empathy find that heterosexual women are less likely to feel empathy for lesbians and (especially) gay men relative to heterosexual women in pain (Groth et al., 2012), people have a stronger empathic response to seeing a friend in pain relative to a stranger (Meyer et al., 2013), and White and Asian individuals have a stronger empathic response when seeing someone of the same race in pain (Xu et al., 2009).

Of course, individuals without histories of self-harm or peer victimization are capable of being empathetic, caring, and overall amazing friends with individuals who do have a history of self-harm. We are simply suggesting that the greater empathic effort involved in such friendships among people with dissimilar histories may make them less inclined to form friendships with 
those peers as often as they may form friendships with peers whose history bears more semblance to their own. That difference in likelihood may be indicative of deselection.

At the same time, individuals who have engaged in self-harm may be less likely to try and form friendships with peers who lack some semblance of oppressive experiences. . Robinson et al. (2020) is instructive here. International students who moved to Canada with the best of postracial intentions ended up forming primarily homophilous friendships. This was due to the emotionally utilitarian calculations they began making as they came to accept the unfortunate reality that diversity is not inclusion. In discussing their interviews with students, Robinson et al. (2020) stated that “Canadians' resistance to international students' friendships block the possibility for meaningful intercultural interaction" such that the "interactions with Canadians provide risks of rejection that appear to outweigh the benefits." As a result of this cultural deselection, international students proceed with a strong preference for homophilous social circles in their ongoing interpersonal experiences as university students in Canada.

We suggest that a similar process takes place among individuals who have engaged in self-harm and the interpersonal bonds that they form. They may have a sense within the first few minutes of interacting with someone (or even just observing someone) whether or not that individual is someone worth investing friendship energy into. In short, past experiences of deselection in high-school may underlie the preferences that influence individuals' friendships in college.

\section{Limitations}

This study is limited in several aspects. First, there was no assessment of individuals' experience of rejection in previous attempts to befriend peers who did not suffer from bullying, or (perhaps counterintuitively) their rejection of socially popular peers who made salient efforts 
to form an interpersonal relationship with them. Such insights are critical to disentangle the effects of preference homophily from deselection (network constraint) and contagion (socialization). Recent homophily research has demonstrated the potential of social networking analyses to provide broader insights into individuals' interpersonal relationships (see Boutyline \& Willer, 2018; Karimi et al., 2018; Messias et al., 2017; Noon et al., 2019). Moreover, the cross-sectional nature of the research design suggests that care should be taken in the interpretation of the degree to which deselection, preference, and peer socialization influenced the formation of participants' interpersonal relationships.

In addition to this, there was no measure to control the social desirability bias within the study. Specifically, social desirability bias illustrates that participants are more likely to respond in a manner in which they would be viewed more socially desirable than others (Grimm, 2010). As the survey itself measured undesirable experiences, such as bullying and self-harm, participants that indicated that they were victims of these experiences are presumed to be accurate. As bullying and self-harm are difficult topics that are not typically publicly discussed with others, it is likely that participants are not socially influenced to indicate that they have been victimized for the purposes of this study. However, there may have been participants who did not feel comfortable or open to indicating that they have been victimized under the influence of social desirability. Thus, distinct measures to prevent social desirability bias, such as including forced-choice questions, may further ensure that participants respond accurately (Grimm, 2010). It is noteworthy that research by Eisenberg et al. (2005) on unhealthy weight control behaviors had participants report on their perceptions of their friends' dieting behavior, whereas we had subjects report on their knowledge as to whether or not their friend had, in fact, engaged in selfharm. 
Though the finding of self-harm homophily, even in the absence of a self-reported history of bullying, is conceptually consistent with implicit homophily (Jacoby-Senghor, 2014), it is conceivable that explicit ingroup identification may occur through salient cues such as scars on someone's arm that are perceived as the outcome of self-harm. Unfortunately, no measure was included to assess whether visible scars, burns, tattoos, or other symbolic body markings influenced initial impressions during the friendship formation process. Of course, the identification of scars on someone's body does not indicate that the individual has engaged in non-suicidal self-injury. A large scar may be obtained through athletic competition and attempting to give a cat a bath may result in multiple small scars in the same location. Indeed, an assessment of scar salience in future research should consider the number of scars and the size of the scar(s), among other factors.

Furthermore, assessments of participants' weight, height, gender identity, and (for those in relationships) the race, sex, and sexual orientation of their romantic partner, would have provided more comprehensive insight into other individual and dyadic factors that influence relationships formation. As similarity and reciprocity are essential factors in friendship formation amongst adolescents, individuals are more likely to befriend someone of the same race and gender (Clark \& Ayers, 1992). Specifically, Black adolescents were more willing to make crossrace friendships than their White peers within the classroom, which was not necessarily reciprocated by their White peers within the predominantly White school. Due to this racial inequality, cross-race dyads were less likely to be formed by the White students than their Black counterparts (Clark \& Ayers, 1992). Moreover, the implicit homophily research by JacobySenghor (2014) found that racially prejudiced individuals were less likely to befriend someone of the same race, which was associated with racial outgroups. Just like the adage, "You are judged 
by the company you keep," relationships have the potential to be created or avoided based on one's affiliations as well as one's characteristics.

Another limitation in the current study was failing to consider bystanders, as their reactions to victimization scenarios are likely relevant in victims' friendship formation process. For instance, bystanders may fail to adequately empathize with the experience of bullied peers (Martocci, 2019), may hold a higher threshold for what constitutes emotional pain for peers of some ethnoracial groups relative to others (Deska et al., 2020), may show more of a neural response upon witnessing a friend's social pain compared to a stranger's (Meyer et al., 2013), and may dissociate from bullied peers to avoid becoming victims of bullying themselves (Machackova et al., 2016; Salmivalli, 2001). In addition, the bystander effect illustrates that an individual's likelihood of helping decreases when there is a larger audience, whether in-person or online (Fischer et al., 2011; Machackova, 2016). As aptly noted by Martocci (2019, p. 2), "current anti-bullying initiatives that privilege bystander intervention may be putting the cart before the horse, assuming the peer cohort is positioned to intercede." Given the myriad factors that may influence bystanders' behavior, they should be considered in future research on implicit homophily among bullied individuals and those that engage in self-harm.

Interestingly, the diversity of our sample is another limitation. It may be the case that an international respondent who was born and raised in India defines his or her high school physical bullying experiences differently than a Chinese American respondent who was born and raised in Canton, Ohio, defines his or her high school relational bullying experiences. Retrospective reports already present a unique challenge without the added complication of cross-cultural differences in bullying properties. Furthermore, respondents may have different definitions of bullying, regardless of their cultural and socioeconomic backgrounds. This difference could have 
impacted their answers to questions about the presence and severity of bullying that they, their friends, or their romantic partners may have experienced.

It would be interesting to determine whether the specific form of bullying that one has experienced influences interpersonal relationship development. For instance, a male who experienced relational aggression may be more likely to develop a female friendship network, and a female who experienced physical aggression may be more likely to develop a male friendship network (Burton et al., 2007). Furthermore, most of our respondents reported that they endured bullying before entering high school. It is possible that being bullied in elementary school or middle school, and the degree to which it increased or decreased over time, played a role in the kinds of interpersonal relationships they formed in early adulthood. Such an analysis would likely have to be longitudinal given the potential of contamination as retrospective crosssectional analyses extend further back in time (i.e., the tradeoff between a longer personal history ark and data that is increasingly subject to false memories and missing information).

\section{Conclusion}

These findings build on implicit homophily research by Jacoby-Senghor (2014) and add to the existing literature on oppression homophily by considering bully victimization as a relevant interpersonal dimension that contributes to forming individuals' social networks. Future research could ascertain the underlying mechanism(s) that produce category boundaries in close relationship patterns for group memberships that are not temporally available (i.e., bullied in the past) or visually perceptible. 


\section{References}

Alford, J. R., Hatemi, P. K., Hibbing, J. R., Martin, N. G., \& Eaves, L. J. (2011). The politics of mate choice. The Journal of Politics, 73(2), 362-379. https://doi.org/10.1017/S0022381611000016

Allen, J. L., \& Post, D. L. (2004). Source valence in assessing candidate image in a local election. Communication Research Reports, 21(2), 174-187. https://doi.org/10.1080/08824090409359979

Alstott, J., Madnick, S., \& Velu, C. (2014). Homophily and the speed of social mobilization: the effect of acquired and ascribed traits. PloS one, 9(4), e95140 https://doi.org/10.1371/journal.pone.0095140

Andersen, B. L., Yang, H. C., Farrar, W. B., Golden-Kreutz, D. M., Emery, C. F., Thornton, L. M., Young, D. C., \& Carson III, W. E. (2008). Psychologic intervention improves survival for breast cancer patients: a randomized clinical trial. Cancer, 113(12), 34503458. https://doi.org/10.1002/cncr.23969

Bargh, J. A., Lombardi, W. J., \& Higgins, E. T. (1988). Automaticity of chronically accessible constructs in person $\mathrm{x}$ situation effects on person perception: It's just a matter of time. Journal of Personality and Social Psychology, 55(4), 599-605. https://doi.org/10.1037/0022-3514.55.4.599

Borowsky, I. W., Taliaferro, L. A., \& McMorris, B. J. (2013). Suicidal thinking and behavior among youth involved in verbal and social bullying: Risk and protective factors. Journal of adolescent health, 53(1), S4-S12.

https://doi.org/10.1016/j.jadohealth.2012.10.280 
Boutyline, A., \& Willer, R. (2017). The social structure of political echo chambers: Variation in ideological homophily in online networks. Political Psychology, 38(3), 551-569. https://doi.org/10.1111/pops.12337

Burton, L. A., Hafetz, J., \& Henninger, D. (2007). Gender differences in relational and physical aggression. Social Behavior and Personality: an international journal, 35(1), 41-50. https://doi.org/10.2224/sbp.2007.35.1.41

Cacioppo, J. T., Hawkley, L. C., \& Berntson, G. G. (2003). The anatomy of loneliness. Current directions in psychological science, 12(3), 71-74. https://doi.org/10.1111\%2F1467$\underline{8721.01232}$

Cacioppo, J. T., Hughes, M. E., Waite, L. J., Hawkley, L. C., \& Thisted, R. A. (2006). Loneliness as a specific risk factor for depressive symptoms: cross-sectional and longitudinal analyses. Psychology and aging, 21(1), 140. https://doi.org/10.1037/0882-7974.21.1.140

Cairns, R. B., Cairns, B. D., Neckerman, H. J., Gest, S. D., \& Gariepy, J. L. (1988). Social networks and aggressive behavior: Peer support or peer rejection? Developmental psychology, 24(6), 815. https://doi.org/10.1037/0012-1649.24.6.815

Cawley, J., Joyner, K., \& Sobal, J. (2006). Size matters: The influence of adolescents' weight and height on dating and sex. Rationality and Society, 18(1), 67-94. https://doi.org/10.1177\%2F1043463106060153

Clark, M. L., \& Ayers, M. (1992). Friendship similarity during early adolescence: Gender and racial patterns. The Journal of psychology, 126(4), 393-405. https://doi.org/10.1080/00223980.1992.10543372 
Cortland, C. I., Craig, M. A., Shapiro, J. R., Richeson, J. A., Neel, R., \& Goldstein, N. J. (2017). Solidarity through shared disadvantage: Highlighting shared experiences of discrimination improves relations between stigmatized groups. Journal of Personality and Social Psychology, 113(4), 547. https://doi.org/10.1037/pspi0000100

Crosnoe, R., Frank, K., \& Mueller, A. S. (2008). Gender, body size and social relations in American high schools. Social Forces, 86(3), 1189-1216, https://doi.org/10.1353/sof.0.0004

Deska, J. C., Kunstman, J., Lloyd, E. P., Almaraz, S. M., Bernstein, M. J., Gonzales, J. P., \& Hugenberg, K. (2020). Race-based biases in judgments of social pain. Journal of Experimental Social Psychology, 88, 103964. https://doi.org/10.1016/j.jesp.2020.103964

DeVoe, J. F., Peter, K., Noonan, M., Snyder, T. D., \& Baum, K. (2005). Indicators of school crime and safety: 2005 (NCES 2006-001/NCJ 210697). Washington, DC: U.S. Government Printing Office.

Distel, M. A., Rebollo-Mesa, I., Abdellaoui, A., Derom, C. A., Willemsen, G., Cacioppo, J. T., \& Boomsma, D. I. (2010). Familial resemblance for loneliness. Behavior genetics, 40(4), 480-494. https://doi.org/10.1007/s10519-010-9341-5

Eisenberg, M. E., Neumark-Sztainer, D., Story, M., \& Perry, C. (2005). The role of social norms and friends' influences on unhealthy weight-control behaviors among adolescent girls. Social Science \& Medicine, 60(6), 1165-1173. https://doi.org/10.1016/j.socscimed.2004.06.055

Eisenberger, N. I. (2012). Broken hearts and broken bones: A neural perspective on the similarities between social and physical pain. Current Directions in Psychological Science, 21, 42-47. https://doi.org/10.1177\%2F0963721411429455 
Eisenberger, N. I., \& Lieberman, M. D. (2004). Why rejection hurts: a common neural alarm system for physical and social pain. Trends in cognitive sciences, 8(7), 294-300. https://doi.org/10.1016/j.tics.2004.05.010

Evans, T. S., Lambiotte, R. \& Panzarasa, P. (2011). Community structure and patterns of scientific collaboration in business and management. Scientometrics, 89, 381-396, https://doi.org/10.1007/s11192-011-0439-1

Fidler, J. (1997). The experiment management system. Washington, DC: Sona Systems Ltd.

Fischer, P., Krueger, J. I., Greitemeyer, T., Vogrincic, C., Kastenmüller, A., Frey, D., Heene, M., Wicher, M. \& Kainbacher, M. (2011). The bystander-effect: a meta-analytic review on bystander intervention in dangerous and non-dangerous emergencies. Psychological bulletin, 137(4), 517. https://doi.org/10.1037/a0023304

Fowler, J. H., Settle, J. E., \& Christakis, N. A. (2011). Correlated genotypes in friendship networks. Proceedings of the National Academy of Sciences, 108(5), 1993-1997. https://doi.org/10.1073/pnas.1011687108

Franklin, J. C., Puzia, M. E., Lee, K. M., Lee, G. E., Hanna, E. K., Spring, V. L., \& Prinstein, M. J. (2013). The nature of pain offset relief in nonsuicidal self-injury: A laboratory study. Clinical Psychological Science, 1(2), 110-119. https://doi.org/10.1177\%2F2167702612474440

Galupo, M. P. (2007). Friendship patterns of sexual minority individuals in adulthood. Journal of Social and Personal Relationships, 24(1), 139-151. https://doi.org/10.1177/0265407506070480 
Goldstein, S. B. (2013). Predicting college students' intergroup friendships across race/ethnicity, religion, sexual orientation, and social class. Equity \& Excellence in Education, 46(4), 502-519. https://doi.org/10.1080/10665684.2013.838114

Greco, L. A., Freeman, K. E., \& Dufton, L. (2007) Overt and relational victimization among children with frequent abdominal pain: Links to social skills, academic functioning, and health service use. Journal of Pediatric Psychology, 32(3), 319-329, https://doi.org/10.1093/jpepsy/js1016

Grimm, P. (2010). Social desirability bias. Wiley international encyclopedia of marketing. $\underline{\text { https://doi.org/10.1002/9781444316568.wiem02057 }}$

Groth, C. M., Bourn, J. R., Maurer, L., \& Terry, C. P. (2012). Effects of Sexual Orientation on Reactive Empathy Expression in Women. Psi Chi Journal of Psychological Research, 17(4). https://cdn.ymaws.com/www.psichi.org/resource/resmgr/journal_2012/Winter12JNGroth $\underline{\text { pdf }}$

Hammen, C., Burge, D., \& Adrian, C. (1991). Timing of mother and child depression in a longitudinal study of children at risk. Journal of Consulting and Clinical Psychology, 59(2), 341-345. https://doi.org/10.1037/0022-006X.59.2.341

Hatzenbuehler, M. L., Schwab-Reese, L., Ranapurwala, S. I., Hertz, M. F., \& Ramirez M. R. (2015). Associations between antibullying policies and bullying in 25 states. JAMA Pediatr, 169(10). https://doi:10.1001/jamapediatrics.2015.2411

Hinduja, S., \& Patchin, J. W. (2010). Bullying, cyberbullying, and suicide. Archives of suicide research, 14(3), 206-221. https://doi.org/10.1080/13811118.2010.494133 
Hofstra, B., Corten, R., Tubergen, F. V., \& Ellison, N. B. (2017). Sources of segregation in social networks: A novel approach using Facebook. American Sociological Review, 82(3), 625-656, https://doi.org/10.1177/0003122417705656

Huber, G., \& Malhotra, N. (2013). Dimensions of Political Homophily: Isolating Choice Homophily along Political Characteristics. Working Paper. Retrieved from http://citeseerx.ist.psu.edu/viewdoc/download?doi=10.1.1.709.386\&rep=rep1\&type=pdf.

Huber, G. A., \& Malhotra, N. (2017). Political homophily in social relationships: Evidence from online dating behavior. The Journal of Politics, 79(1), 269-283. https://doi.org/10.1086/687533

Iyer-Eimerbrink, P. A., \& Jensen-Campbell, L. A. (2019). The long-term consequences of peer victimization on physical and psychological health: A longitudinal study. Journal of Applied Biobehavioral Research, 24(4), e12174. https://doi.org/10.1111/jabr.12174

Jacoby-Senghor, D. S. (2014). Implicit homophily: Effects of implicit outgroup bias on ingroup affiliation. Jacoby-Senghor, D. S. Dissertation Abstracts International: Section B: The Sciences and Engineering, 75.

Jennings, M. K., Stoker, L., \& Bowers, J. (2009). Politics across generations: Family transmission reexamined. The Journal of Politics, 71(3), 782-799. https://doi.org/10.1017/S0022381609090719

Joiner Jr, T. E. (1999). The clustering and contagion of suicide. Current directions in psychological science, 8(3), 89-92. https://doi.org/10.1111\%2F1467-8721.00021

Joiner Jr, T. E., \& Katz, J. (1999). Contagion of depressive symptoms and mood: Meta-analytic review and explanations from cognitive, behavioral, and interpersonal viewpoints. Clinical Psychology: Science and Practice, 6(2), 149-164. https://doi.org/10.1093/clipsy.6.2.149 
Juvonen, J., Nishina, A., \& Graham, S. (2000). Peer harassment, psychological adjustment, and school functioning in early adolescence. Journal of Educational Psychology, 92(2), 349359. https://doi.org/10.1037/0022-0663.92.2.349

Kao, G., \& Joyner, K. (2004). Do race and ethnicity matter among friends? Activities among interracial, interethnic, and intraethnic adolescent friends. The Sociological Quarterly, 45, 557- 573, https://doi.org/10.1111/j.1533-8525.2004.tb02303.x

Karimi, F., Génois, M., Wagner, C., Singer, P., \& Strohmaier, M. (2018). Homophily influences ranking of minorities in social networks. Scientific reports, 8(1), 1-12. https://doi.org/10.1038/s41598-018-29405-7

Lewis, K., \& Kaufman, J. (2018). The conversion of cultural tastes into social network ties. American journal of sociology, 123(6), 1684-1742. https://doi.org/10.1086/697525

Logan, L. S. (2013). Status homophily, sexual identity, and lesbian social ties. Journal of homosexuality, 60(10), 1494-1519. https://doi.org/10.1080/00918369.2013.819244

Lou, J. K., Park, K., Cha, M., Park, J., Lei, C. L., \& Chen, K. T. (2013, May). Gender swapping and user behaviors in online social games. In Proceedings of the 22nd international conference on World Wide Web (pp. 827-836). https://doi.org/10.1145/2488388.2488460

Macmillan, R. \& Hagan, J. (2004). Violence in the transition to adulthood: Adolescent victimization, education, and socioeconomic attainment in late life. Journal of Research on Adolescence, 14(2), 127-158, https://doi.org/10.1111/j.1532-7795.2004.01402001.x

Machackova, H., Dedkova, L., Sevcikova, A., \& Cerna, A. (2016). Empathic responses by cyberbystanders: the importance of proximity. Journal of Youth Studies, 19(6), 793-804. https://doi.org/10.1080/13676261.2015.1112882 
Martocci, L. (2019). The Capacity to Intervene: Bullying, Social Pain, and Bystander Empathy. Sociological Inquiry. https://doi.org/10.1111/soin.12288

Mayer, A. \& Puller, S. L. (2008). The old boy (and girl) network: Social network formation on university campuses. Journal of Public Economics, 92(1-2), 329-347, https://doi.org/10.1016/j.jpubeco.2007.09.001

McCroskey, L. L., McCroskey, J. C., \& Richmond, V. P. (2006). Analysis and improvement of the measurement of interpersonal attraction and homophily. Communication Quarterly, 54(1), 1-31. https://doi.org/10.1080/01463370500270322

McCroskey, J. C., Richmond, V. P., \& Daly, J. A. (1975). The development of a measure of perceived homophily in interpersonal communication. Human Communication Research, 1(4), 323-332, https://doi.org/10.1111/j.1468-2958.1975.tb00281.x

McPherson, M., Smith-Lovin, L., \& Cook, J. M. (2001). Birds of a feather: Homophily in social networks. Annual Review of Sociology, 27(1), 415-444.

https://doi.org/10.1146/annurev.soc.27.1.415

Mehta, C.M., Hojjat, M., Smith, K.R., \& Ayotte, B. J. (2017). Associations between gender segregation and gender identity in college students. Sex Roles, 76, 694-704, https://doi.org/10.1007/s11199-016-0685-Z

Meland, E., Rydning, J. H., Lobben, S., Breidablik, H. J., \& Ekeland, T. J. (2010). Emotional, self-conceptual, and relational characteristics of bullies and the bullied. Scandinavian Journal of Public Health, 38(4), 359-367.

https://doi.org/10.1177\%2F1403494810364563 
Mercer, S. H., \& Derosier, M. E. (2010). Selection and socialization of internalizing problems in middle childhood. Journal of Social and Clinical Psychology, 29(9), 1031-1056. https://doi.org/10.1521/jscp.2010.29.9.1031

Messias, J., Vikatos, P., \& Benevenuto, F. (2017, August). White, man, and highly followed: Gender and race inequalities in Twitter. In Proceedings of the International Conference on Web Intelligence (pp. 266-274). https://doi.org/10.1145/3106426.3106472

Meyer, M. L., Masten, C. L., Ma, Y., Wang, C., Shi, Z., Eisenberger, N. I., \& Han, S. (2013). Empathy for the social suffering of friends and strangers recruits distinct patterns of brain activation. Social cognitive and affective neuroscience, 8(4), 446-454. https://doi.org/10.1093/scan/nss019

Neuberg, S. L. \& Sng, O. (2013). A life history theory of social perceptions: Stereotyping at the intersections of age, sex, ecology (and race). Social Cognition, 31, 696-711, https://doi.org/10.1521/soco.2013.31.6.696

Noon, E. J., \& Meier, A. (2019). Inspired by Friends: Adolescents' Network Homophily Moderates the Relationship Between Social Comparison, Envy, and Inspiration on Instagram. Cyberpsychology, Behavior, and Social Networking, 22(12), 787-793. https://doi.org/10.1089/cyber.2019.0412

Olweus, D. (1994). Bullying at school: basic facts and effects of a school based intervention program. Journal of child psychology and psychiatry, 35(7), 1171-1190. https://doi.org/10.1111/j.1469-7610.1994.tb01229.x

Patacchini, E., \& Zenou, Y. (2016). Social networks and parental behavior in the intergenerational transmission of religion. Quantitative Economics, 7(3), 969-995. https://doi.org/10.3982/QE506 
Peguero, A. A. (2011). Violence, schools, and dropping out: Racial and ethnic disparities in the educational consequence of student victimization. Journal of Interpersonal Violence, 26(18), 3753-3772, https://doi.org/10.1177/0886260511403764

Peguero, A. A., \& Williams, L. M. (2013). Racial and ethnic stereotypes and bullying victimization. Youth \& Society, 45(4), 545-564. https://doi.org/10.1177\%2F0044118X11424757

Phua, J. (2012). Use of social networking sites by sports fans: Implications for the creation and maintenance of social capital. Journal of Sports Media, 7(1), 109-132. http://doi:10.1353/jsm.2012.0006.

Pinel, E. C., \& Long, A. E. (2012). When I's meet: Sharing subjective experience with someone from the outgroup. Personality and Social Psychology Bulletin, 38(3), 296-307. https://doi.org/10.1177\%2F0146167211433878

Pinel, E. C., Long, A. E., Landau, M., Alexander, K., \& Pyszczynski, T. (2006). Seeing I to I: A pathway to interpersonal connectedness. Journal of Personality and Social Psychology, 90(2), 243-257. https://doi.org/10.1037/0022-3514.90.2.243

Prinstein, M. J., Heilbron, N., Guerry, J. D., Franklin, J. C., Rancourt, D., Simon, V., \& Spirito, A. (2010). Peer influence and nonsuicidal self injury: Longitudinal results in community and clinically-referred adolescent samples. Journal of abnormal child psychology, 38(5), 669-682. https://doi.org/10.1007/s10802-010-9423-0

Quillian, L., \& Campbell, M. E. (2003). Beyond black and white: The present and future of multiracial friendship segregation. American Sociological Review, 540-566. https://doi.org/10.2307/1519738 
Qureshi, S. S. (2011). Perceptions of school bullying and racist bullying in a Northern city (Doctoral dissertation, North Umbria University).

Rivers, I., \& Smith, P. K. (1994). Types of bullying behaviour and their correlates. Aggressive behavior, 20(5), 359-368. https://doi.org/10.1002/1098-2337

Robinson, B. A. (2016). The Quantifiable-Body Discourse: "Height-Weight Proportionality” and Gay Men's Bodies in Cyberspace. Social Currents, 3(2), 172-185. https://doi.org/10.1177\%2F2329496515604638

Robinson, O., Somerville, K., \& Walsworth, S. (2020). Understanding friendship formation between international and host-national students in a Canadian university. Journal of International and Intercultural Communication, 13(1), 49-70. https://doi.org/10.1080/17513057.2019.1609067

Rosen, P. J., Milich, R., \& Harris, M. J. (2007). Victims of their own cognitions: Implicit social cognitions, emotional distress, and peer victimization. Journal of Applied Developmental Psychology, 28(3), 211-226. https://doi.org/10.1016/j.appdev.2007.02.001

Rosenhan, D. L. (1973). On Being Sane in Insane Places. Science, 179(4070), 250-258. doi: https://doi.org/10.1126/science.179.4070.250

Rudolph, K. D., Flynn, M., \& Abaied, J. L. (2008). A developmental perspective on interpersonal theories of youth depression. In J. R. Z. Abela \& B. L. Hankin (Eds.), Handbook of depression in children and adolescents (p. 79-102). The Guilford Press.

Salmivalli, C. (2001). Feeling good about oneself, being bad to others? Remarks on self-esteem, hostility, and aggressive behavior. Aggression and violent behavior, 6(4), 375-393. https://doi.org/10.1016/S1359-1789(00)00012-4 
Schaefer, D. R., Kornienko, O., \& Fox, A. M. (2011). Misery does not love company: Network selection mechanisms and depression homophily. American Sociological Review, 76(5), 764-785. https://doi.org/10.1177\%2F0003122411420813

Skopek, J., Schulz, F., \& Blossfeld, H. (2011). Who contacts whom? Educational homophily in online mate selection. European Sociological Review, 27(2), 180-195, https://doi.org/10.1093/esr/jcp068

Smith, J. A., McPherson, M., \& Smith-Lovin, L. (2014). Social distance in the United States: Sex, race, religion, age, and education homophily among confidants, 1985 to 2004. American Sociological Review, 79(3), 432-456. https://doi.org/10.1177/0003122414531776

Smith, S., Maas, I., \& Tubergen, F. V. (2014). Parental influence on friendships between native and immigrant adolescents. Journal of Research on Adolescence, 25(3), 580-59, https://doi.org/10.1111/jora.12149

Stearns, E., Buchmann, C., \& Bonneau, K. (2009). Interracial friendships in the transition to college: Do birds of a feather flock together once they leave the nest?. Sociology of Education, 82(2), 173-195. https://doi.org/10.1177\%2F003804070908200204

Stevens, E. A., \& Prinstein, M. J. (2005). Peer contagion of depressogenic attributional styles among adolescents: A longitudinal study. Journal of Abnormal Child Psychology, 33(1), 25-37. https://doi.org/10.1007/s10802-005-0931-2

Swearer, S. M., Espelage, D. L., Vaillancourt, T., \& Hymel, S. (2010). What can be done about school bullying?: Linking research to educational practice. Educational Researcher, 39(1), 38-47. https://doi.org/10.3102/0013189X09357622 
Syed, M. \& Juan, M. J. D. (2012). Birds of an ethnic feather? Ethnic identity homophily among college-age friends. Journal of Adolescence, 35(6), 1505-1514, https://doi.org/10.1016/j.adolescence.2011.10.012

Turner, H. A., Vanderminden, J., Finkelhor, D., Hamby, S., \& Shattuck, A. (2011). Disability and victimization in a national sample of children and youth. Child maltreatment, 16(4), 275-286. https://doi.org/10.1177\%2F1077559511427178

Ueno, K., Wright, E. R., Gayman, M. D., \& McCabe, J. M. (2012). Segregation in gay, lesbian and bisexual youth's personal networks: Testing structural constraint, choice homophily and compartmentalization hypotheses. Social Forces, 90(3), 971-991, https://doi.org/10.1093/sf/sor022

Utz, S. \& Jankowski, J. (2015). Making "Friends" in a virtual world: The role of preferential attachment, homophily, and status. Social Science Computer Review, 34(5), 546-566, https://doi.org/10.1177/0894439315605476

Vervoort, M. H. M., Scholte, R. H. J., \& Scheepers, P. L. H. (2011) Ethnic composition of school classes, majority-minority friendships, and adolescents' intergroup attitudes in the Netherlands. Journal of Adolescence, 34(2), 257-267,

\section{https://doi.org/10.1016/j.adolescence.2010.05.005}

Weisz, C., \& Wood, L. F. (2005). Social identity support and friendship outcomes: A longitudinal study predicting who will be friends and best friends 4 years later. Journal of Social and Personal Relationships, 22(3), 416-432.

https://doi.org/10.1177\%2F0265407505052444 
Wejnert, C. (2010). Social network analysis with respondent-driven sampling data: A study of racial integration on campus. Social Networks, 32, 112-124, https://doi.org/10.1016/j.socnet.2009.09.002.

Williams, K. D., Bernieri, F. J., Faulkner, S. L., Gada-Jain, N. \& Grahe, J. E. (2000). The scarlet letter study: Five days of social ostracism. Journal of Personal and Interpersonal Loss, 5(1), 19-63. https://doi.org/10.1080/10811440008407846

Williams, K. D. \& Sommer, K. L. (1997). Social ostracism by coworkers: Does rejection lead to loafing or compensation? The Society for Personality and Social Psychology, 23(7), 693706. https://doi.org/10.1177/0146167297237003

Winstead, B. A. (1986). Sex differences in same-sex friendships. In Friendship and social interaction (pp. 81-99). Springer, New York, NY. https://doi.org/10.1007/978-1-4612$\underline{4880-4 \quad 5}$

Wright, K. (2000). Perceptions of on-line support providers: An examination of perceived homophily, source credibility, communication and social support within on-line support groups. Communication Quarterly, 48(1), 44-59. https://doi.org/10.1080/01463370009385579

Xu, X., Zuo, X., Wang, X., \& Han, S. (2009). Do you feel my pain? Racial group membership modulates empathic neural responses. Journal of Neuroscience, 29(26), 8525-8529. https://doi.org/10.1523/JNEUROSCI.2418-09.2009 